\title{
Helping tomorrow's social professionals to learn about social robotics
}

\section{Perry Share, John Pender}

Department of Social Sciences, Institute of Technology Sligo, Ireland.

\begin{abstract}
This paper identifies that social robotics and autonomous technologies will inevitably impact on the field of care for human beings. Those currently employed in caring roles, and those about to enter these roles, are generally ill-prepared to respond to this challenge: whether it is to develop the skills to work alongside such technologies or to critically engage with their development. The paper outlines a current Erasmus+ funded international project (PRoSPEro) that brings together social roboticists, educators, learners, practitioners and policymakers in order to develop, pilot, assess and deploy innovative pedagogical materials to address the gap in provision. It also describes a locally-generated learning opportunity within futures studies that facilitates learners to engage directly with these new technologies. The paper provides ideas for strategies and techniques to successfully engage learners from social science and therapeutic-based fields to engage with urgent contemporary technological issues.
\end{abstract}

Keywords: social robotics; pedagogy; EU project; technology; innovation. 


\section{Introduction}

We are all touched by the health and care systems. As we age, we need more care, while the supply of many categories of health and care workers is failing to meet demand, due to demographic changes and other forces. Digital technology is now increasingly part of the provision of human services, but is often not well understood, in terms of technology, ethics, economics or systems. While technologists strive for constant improvement, professional practice knowledge and user perspectives are often underused in technology development, leading to failed innovations and missed opportunities.

Of particular interest has been the explosion in Human Robot Interaction [HRI]. Topics emerging from numerous global research centres include: artificial empathy; robots in education; robotics and human care; impact of gender and personality in HRI; anthropomorphic social robots and numerous other issues and applications (Vincent et al 2015). Notwithstanding a number of false starts and failed enterprises, such as the Kuri, Jibo and Anki robots, there continues to be substantial global financial investment in social robotics by major technology and electronics firms such as Toyota, Midea and Bosch.

Though not yet widely distributed in the field of care in Europe, the development of social robotics continues apace, with numerous examples now in prototype or production stage. Application is a current reality in, for example, the fields of dementia (eg Paro); autism (Nao), early years education (Cozmo), companionship for children in long-term hospital stays (AVI), and care of older people more generally (Mylo) (Fig. 1).
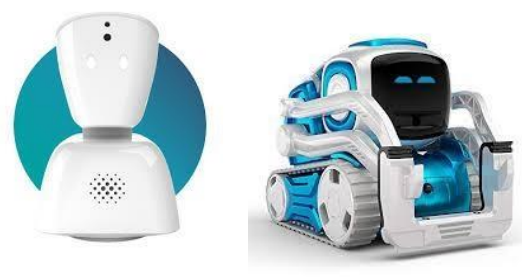

AV1

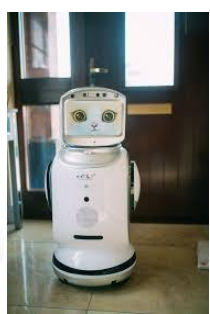

Mylo

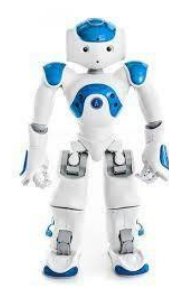

Nao

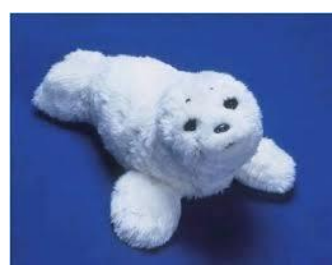

Paro

Figure 1. Some social robots currently in production and use, in care and education settings

\section{The social significance of social robotics}

Social professionals must engage in social analysis of these novel technologies. There is now extensive discussion of the social shaping of robotic technologies (Markoff, 2015; Broussard, 2018) and of their impact at global, community, workplace and individual level (Vincent et al, 2015; Willcocks \& Lacity, 2016; Kiggins, 2018). Researchers offer widely diverse assessments of the impact of autonomous and robotic technologies, but most see a 
significant technological shift, with future societal impacts that exceed those of other recent and contemporary technologies. This 'technological determinist' view (Neven \& Leeson, 2015 , p. 85) prevails in writing about robots and society. A smaller literature exists on how these technologies have been socially and culturally shaped (Sone, 2017) and there is less still on 'mutual shaping' processes at play (Neven \& Leeson, 2015; Winkle et al, 2019).

Driven at least partially by such analyses, there is a strong view that societies should explore adapted or new types of institutional innovation, such as codes of ethics, laws, regulations and regulatory regimes, to manage, regulate and ultimately control these developments. Technologies already developed and applied (such as certain types of algorithmic decision-making; the widespread use of some social robots) have already led to important concerns over regulation and have raised key ethical challenges (Eubanks, 2018).

\section{The challenges for social professionals}

These novel technologies will 'augment' the work of social professionals, such as social pedagogues, social care practitioners, aged care workers, social workers and early years practitioners and occupational therapists, but little thought has been given to the impact on their everyday tasks, career development and professional identity; less to how these challenges can inform professional formation, including curriculum content; pedagogy; and regulation and professional standards of proficiency (Share \& Pender, 2018).

Like any technology, robotics will not be neutral in its social impacts. The field is highly gendered: most robotics researchers (with important exceptions) are male and located in the global North; those involved in the delivery of care remain predominantly female, often drawn from the global South. Those in receipt of care - such as those with dementia, young children or those on the autism spectrum - are often the most vulnerable in our society. It will also be important to be sensitive to intended and unintended broader social impacts.

\section{The challenges for social professional education and training}

Despite these incipient trends and developments, educational programmes designed to train and educate the social professionals of the future rarely prepare graduates for the technology-infused future that they will encounter. No such programme in Europe specifically exposes students or current social professionals to the reality of social robotics development. The educators, for their part, do not necessarily have the materials, access to robot technology or the pedagogical tool-kits to comprehensively address this issue.

Social professionals' skills are often shaped through educational programmes based on social sciences (sociology, psychology, education); creative arts (drama, visual art); health and therapeutic knowledges; communicative skills and people management. Typically, 
their formation does not expose social professionals to autonomous technologies, such as algorithms, AI and social robotics. They may thus be ill-equipped to encounter them in the workplace or to contribute to related policy-making, implementation or regulation.

We have conducted (2017-2018) three focus groups with social professional educators and students that reveal strong interest, but little knowledge, in the field of social robotics and care; reinforced by participants $(\mathrm{n}=80)$ at an international symposium in Sligo, Ireland (Nov 2017). This finding has been further supported by a subsequent (2019) focus group with physiotherapists within a hospital setting in the North West of Ireland (unpublished data).

\section{PRoSPEro}

In response to this gap, we initiated the PRoSPEro project (Pedagogy of Robotics for the Social Professions in Europe)(Project 2018-1-IE02-KA203-000611). PRoSPEro links the education and training of social professionals to the latest research developments in social robotics. It involves partnerships across Europe ( 5 countries) between social scientists and roboticists; HEIs and local municipalities; service users and care-providers; and amongst teachers, students, practitioners and policy-makers. It seeks to create a transdiciplinary learning community that draws on experienced educators, cutting-edge robotics researchers, practitioners and learners to co-create the necessary pedagogical responses.

The project seeks to identify, operationalise and practice key skills and competencies for working with social robots. It trials a range of educational interventions and resources to explore how best to facilitate the social professionals of the future to learn about future technological challenges. It explores user-centred design and co-creation of social robotic solutions. Outputs of the project will include: development of scoping reports in key areas; a position paper on ethical issues; intensive workshops that involve access to existing social robots; a participatory design workshop to include social robotics researchers, social scientists, students, practitioners and policy-makers; development of effective pedagogies to facilitate learning about social robots. It will combine these approaches into two $(1 \times 20$; 1x10 ECTS) module descriptors for use in social professional education anywhere.

\section{What have we achieved already?}

We have sought to organise this complex field through the completion of five scoping reviews: on defining social robots; ethics; regulation; pedagogy; and key trends and statistics. We have developed two small-scale workshops (Aarhus, Denmark and Valencia, Spain) that have drawn on the direct social robotics experience of one of the partners: the 'Emily' robot baby as deployed in Danish family services. Aarhus participants identified that perhaps humans can learn something about the concept of 'care' from using robots, 
that to imagine 'robot-provided care' forces us think of the essence of care and the uniqueness of being a human. We must think about and deconstruct how human-to-human care may be better than robot-to-human care. These are important and deep-seated ethical issues that are inherent in the topic and that will help to shape future pedagogies.

When the workshop was repeated in Valencia (a large group that included trainee teachers, computer science students and local government personnel), other important concerns arose: for example the surveillance involved in the use of the 'robot baby' to assess the parental capacity of vulnerable young people. The physical presence of the 'robot baby', as it was passed around the classroom, was an important element in the learning process

The next scheduled activity is a Design Workshop hosted at the University of Twente Design Lab. This is aimed to be a highly interactive and exciting experience, that brings together cutting-edge researchers with other participants such as care workers, health professionals, policymakers and students from a variety of European countries.

All of these outputs will be actively disseminated through the digital platforms, multiplier events, relevant media and policy briefs and meetings with education and practice regulators. The materials will be enduring as they will be maintained on a permanent project website (prospero.via.dk/en) and through EPALE (https://epale.ec.europa.eu/en). The overall result will be to develop a trans-European social robotics/care knowledge base amongst social professionals, educators/students, regulators and citizens more broadly. Participants' skills and competences will develop, and they will also develop as citizens who are more engaged (in a critical way) with important and disruptive technologies.

\section{Engaging with the project locally}

In order to leverage the impact of the EU-funded PRoSPEro project, locally-based pedagogical initiatives in relation to autonomous technologies in care are being designed and piloted. One of the authors has been delivering a futures and foresight elective module 'Futures of care, society and welfare' to social care practice and early years education students since 2004; to our knowledge, the only module of its kind offered in Irish higher education. Futures studies broadly seeks to posit 'possible, probable and preferable futures' (Bell, 2005). Originating in the aftermath of World War 2 (Winthorp, 1968; Cornish, 1977), futures studies has intellectually evolved significantly, as has the application of many innovative futures methodologies directed at a plethora of post-industrial societal issues and challenges (Slaughter, 1996; Dator, 2019). It draws upon sociology, economics, politics, psychology, anthropology, and science fiction narratives (Son, 2014).

Students undertaking the module experience a lecture programme spanning 13 weeks/26 hours of contact time. Lectures unpack the building blocks and historical contexts of 
futures studies including an immersion in foresight and forecasting methodologies that evolves to incorporate critical explorations of issues as diverse as the futures of food; education; health and genetics; artificial intelligence (AI) and social robotics; politics and economy. It considers wider assessments of the abilities of advanced societies to sustain welfare provision to vulnerable groups in the contexts of ageing demographics and the ongoing challenges of a global climate crisis and rapid technological change.

Related to the trends in technologies of care outlined above, and drawing on the availability of social robot examplars (Nao, Paro and Cozmo), the assessment strategy for the module was redesigned in early 2020. Learners will be facilitated to demonstrate their awareness of the function, purpose and possibilities of social robots in their anticipated future world of care work. They must also effectively communicate and share their knowledge to carefully selected health and social care audiences.

To this end, learners have been presented with an assessment brief grounded in de Castell's (2010) 'pedagogies of production' teaching and learning philosophy. This offers a multidisciplinary and multimodal array of learning opportunities: 'where learning actors are supported to engage real-world research challenges and design competences, using realworld tools'. It reflects a constructionist rather than an instructionist paradigm of learning (Yanez et al 2019, p.31). Learning by doing enables learners to create authentic artefacts that are presented to 'authentic audiences' selectively invited to participate in and share knowledge production (Thumlert et al, 2015). It empowers learners to use real-world technology tools 'instead of curricularized surrogates' (Yanez et al, 2019, p. 32).

The assessment strategy requires learners to form action learning groups (ALGs) of no more than four members. Each ALG has been advised to identify a social robot or AI entity that members have little or no knowledge of. They must undertake substantial research in order to develop and present an interactive workshop on the futures of care to an audience with little or no prior knowledge of the artefact or its situational functionality. This may involve new ways of using, adapting and/or significantly modifying an existing social robot or AI entity. Learners will be provided with two master classes on approaches to design and user experience and on how to develop affective AI applications.

The learner-led workshops will facilitate the production and dissemination of new knowledge about how social care/early years education undergraduates acquire knowledge and understanding about social robots/AI. They will develop the ability to effectively communicate this knowledge to their peers taking cognisance of the following:

- what is the purpose of the identified social robot/AI algorithm and what care need(s) has it been designed to address?

- what evidence base have the developers drawn up? 
- how has the social robot been received by (a) end-users; (b) service providers?

- how would you assess and evaluate the design and user-friendliness of the social robot/AI algorithm from an end-user and an overall perspective?

- how is the technology being marketed - are there any design/UX issues?

- $\quad$ are there issues that would inhibit the acceptance of the social robot/AI algorithm among service providers? What might these issues be?

- what type of knowledge/understanding do care providers require to effectively cowork with a social robot/AI algorithm?

- what pedagogical framework could be designed to effectively deliver a one-hour learning from demonstration (LfD) training session to a group of health and social care participants on the application of a selected social robot/AI algorithm?

- what resources/supports will be required to deliver this training session?

- how might workshop audiences be encourage to actively engage in the coproduction of knowledge wider participation in the workshop?

\section{Conclusion}

We have identified that social robotics and autonomous technologies will inevitably impact on the field of care for human beings. Those currently in paid (and unpaid) caring roles, and those about to enter these roles, are generally ill-prepared to respond: whether to develop the skills to work alongside such technologies or to be able to critically engage with their development (which may mean mobilising to reject them). We have briefly outlined an Erasmus+ funded international project (PRoSPEro) that is bringing together roboticists, educators, learners, practitioners and policymakers in order to develop, pilot, assess and deploy innovative pedagogical materials to address the gap in provision. In association with PRoSPEro, we have sketched out a locally-generated learning opportunity that facilitates learners to engage directly with these new technologies. We do not know what the future will bring, but we are taking active steps to provide the social professionals of the future with the critical tools to respond, assess and ultimately help to shape it.

\section{References}

Bell, W. (2005) Foundations of futures studies: History, purposes and knowledge. Vol. 1. New Brunswick: Translations.

Broussard, M. (2018) Artificial unintelligence: How computers misunderstand the world. Cambridge [MA]: MIT Press. 
Cornish, E. (ed) (1977) The study of the future. Washington DC: World Future Society.

Dator, J. (2019) Jim Dator: A noticer in time: Selected work 1967-2018. [Anticipation Science, Volume 5]. Cham: Springer.

de Castell, S. (2010) Exquisite attention: From compliance to production. Language and Literacy 2, pp. 4-7. https://doi.org/10.20360/G2G59Z

Eubanks V. (2018) Automating inequality: How high-tech tools profile, police, and punish the poor. New York: St Martin's Press.

Kiggins, R. (ed)(2018) The political economy of robots. London: Palgrave Macmillan.

Markoff, J. (2015) Machines of loving grace: The quest for common ground between humans and robots. New York: Ecco.

Neven, L. \& C. Leeson (2015) 'Beyond determinism: understanding actual use of social robots by older people'. In D. Prendergast \& C. Garattini (eds) Ageing and the digital life course. New York/Oxford: Berghahn. pp. 84-102.

Share, P. \& Pender, J. (2018) Preparing for a robot future? Social professions, social robotics and the challenges ahead. Irish Journal of Applied Social Studies 18(1), Article 4. doi:10.21427/D7472M

Slaughter, R. (1996) The knowledge base of futures studies. Hawthorn: DDM Media.

Son, H. (2015) The history of Western futures studies: an exploration of the intellectual traditions and three-phase periodization. Futures 66. http://dx.doi.org/10.1016/j.futures.2014.12.013

Sone, Y. (2017) Japanese robot culture: Performance, imagination and modernity. London: Palgrave Macmillan.

Thumlert, K., de Castell, S., \& Jenson, J. (2015) Short cuts and extended techniques: Rethinking relations between technology and educational theory. Educational Philosophy and Theory 47(8), pp. 786-803.

Vincent, J., Taipale, S., Sapio, B., Lugano, G. \& Fortunati, L. (eds) (2015) Social Robots from a Human Perspective. Cham: Springer.

Willcocks, L. \& Lacity, M. (2016) Service Automation: Robots and the Future of Work. Stratford-upon-Avon: Steve Brooks Publishing.

Winkle, K., P. Caleb-Solly, A. Turton \& P. Bremner (2019) 'Mutual shaping in the design of socially assistive robots: A case study on social robots for therapy'. International Journal of Social Robotics https://doi.org/10.1007/s12369-019-00536-9

Winthorp, H. (1968) The sociologist and the study of the future. The American Sociologist 2, pp.136-145.

Yanez, G. A., Thumlert, K., de Castell, S., \& Jenson, J. (2019). Pathways to sustainable futures: A 'production pedagogy' model for STEM education. Futures 108, pp.27-36. https://doi.org/10.1016/j.futures.2019.02.021 